\title{
Renewable energy impact in reducing greenhouse gas emissions at local scale: the case study of South Tuscany geothermal fields
}

\author{
S. Bosco, R. M. Pulselli \& S. Bastianoni \\ Department of Chemical and Biosystems Sciences, \\ University of Siena, Italy
}

\begin{abstract}
The energy sector is responsible for the majority of greenhouse gas emissions that cause global warming. The development of renewable energy is a central aim of the European Commission's energy policy. Italy has the principal high temperature geothermal deposits in the EU and alone represents $97.9 \%$ of the total European capacity in 2004. Tuscany has already reached the European goal of $25 \%$ of RES (Renewable Energy Source) established for 2010, thanks to the geothermal energy presence in its territory. Geothermal energy production in the South Tuscany area, which falls into the Siena and Grosseto Provinces, has been developed since 1969 and in 2004 had 2,360 GWh of net energy production. The aim of this paper is to point out the importance of geothermal energy in reducing greenhouse gases emissions at a local scale, carrying out emissions inventories of the concerned Provinces with the IPCC methodology. The electrical energy production in 2000 was enough to cover all the electrical energy consumptions in both Provinces. Applying a strictly geographical approach to the electrical energy consumption, the greenhouse gas net balances for both the Provinces decrease more than $50 \%$ that if we use a responsibility one.

Keywords: greenhouse gas emissions inventory, local scale, renewable energy, geothermal energy, IPCC methodology.
\end{abstract}




\section{Introduction}

The coming into force of the Kyoto Protocol in 2005 imposes to the signatory Nations to activate all the measures needed for the control and the reduction of greenhouse gas emissions, till a global average cut of $5.2 \%$ of 1990 emissions in the period 2008-2012. Renewable Energy Sources (RES) will play in next years a focal rule in reducing the greenhouse gas emissions [1]. RES can help in slowing down the emissions rate from energy sector, the main source of $\mathrm{CO}_{2}$ emissions, due principally to fuels combustion, both for direct use, for transport, residential and industrial use and for electrical energy production in thermoelectric power stations.

European Union put in the strategy for the emissions reduction the substitution of fossil fuels with renewable energies. The aim of the White Paper in 1997 was to attain, by 2010, a minimum penetration of $12 \%$ of renewable energy sources in the European Union. Then the European Parliament and the Council issued the directive $2001 / 77 / \mathrm{EC}$ to facilitate a significant increase in the medium term in renewable generated electricity (RES-E).

Few European Countries have the natural resources necessary for electrical valorization of geothermal energy. Total geothermal gross generation in Europe in 2004 amounts to 5,545 GWh. Italy has the principal high temperature geothermal deposits in the EU, 5,430 GWh gross production, and alone represented $97.9 \%$ of total European capacity in the same year [2]. Geothermal energy production in Italy in 2004 is 5,127 GWh of net production and constitutes the $1.8 \%$ of the national net production for that year.

Geothermal energy production is totally located in Tuscany, in two areas, the first is Larderello zone, where geothermal potentiality as electrical energy source was discovered in 1904, and the second in the South, near Mt. Amiata. This area and Travale-Radicondoli fields are included administratively in two Provinces, Siena and Grosseto.

\subsection{Geothermal energy in Siena and Grosseto Provinces}

Siena and Grosseto Provinces are located in the part of Tuscany with the lower inhabitant's density, respectively 66 and $47 \mathrm{inhab} / \mathrm{km}^{2}$, and their economy based on tertiary and tourism, with an important rule also for agriculture, especially for Grosseto. In the core of this area there are the geothermal fields at foots of Amiata Mountain and in the north of Siena Province the Travale Radicondoli fields.

In South Tuscany geothermal fields have been exploited since the beginning of 20th century and in 2004 five geothermal power plants were in operation, with total net production of 2,360 GWh [3]. These are the only power plants in the two Provinces and all the electricity produced is put in the national distribution network. Direct use of geothermal energy as heat pump systems is not very developed at the moment, the main use is for a greenhouse farm, so this use will not be included in this study, focussing the attention on electrical use only. 
Geothermal energy has in this zone a slow but constant development, and how we can see in Figure 1, Grosseto Province reaches the production of Siena, being over the electrical energy consumption in the last years. Only for 2000 the only geothermal generation is adequate to sustain all the provincial consumption (industrial, residential tertiary and agriculture use) for both the areas. This energy production becomes important at regional scale, where RES are already the $27 \%$ of total energy production.

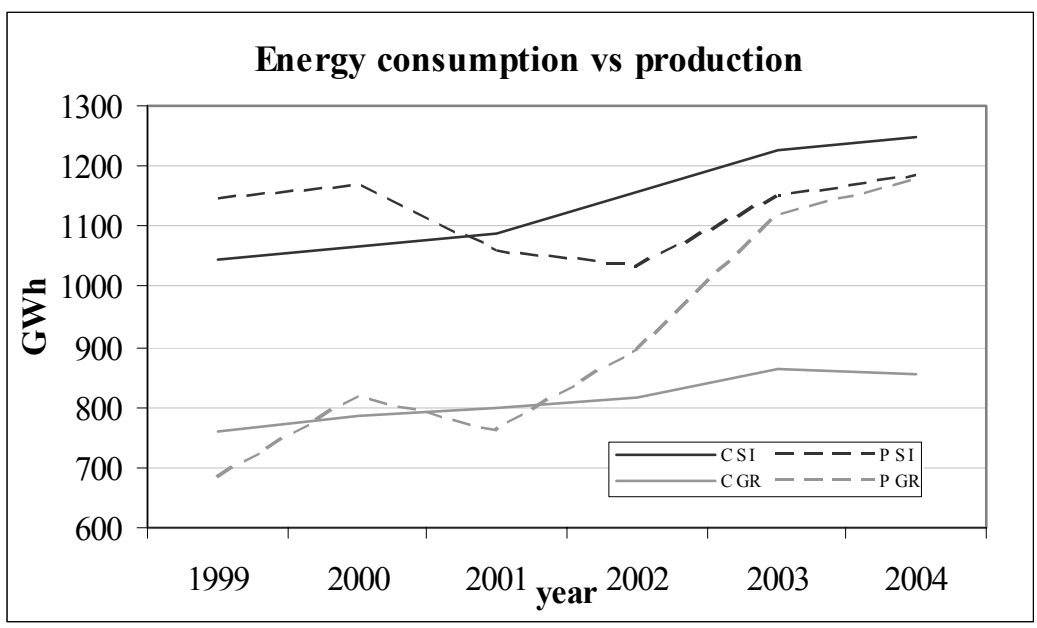

Figure 1: Electrical consumption (C) and geothermal energy production (P) in 2000 for Siena (SI) and Grosseto (GR) Provinces (GWh) [3].

This renewable energy generation can be evaluated in term of emissions saving utilizing IPCC methodology for an emissions inventory at local scale [4].

The greenhouse gas inventories of Siena and Grosseto Provinces have been developed for year 2000, the year in which the geothermal generation can cover all the electrical consumption in the two Provinces at the same time and the emission saving is the maximum possible in the whole area.

The IPCC methodology, based on a geographical approach, has been used for the five sectors of emissions sources (Energy, Industry, Agriculture, Waste and Forestry). This approach has been important most of all in energy sector, to evaluate the emissions of electrical energy generation. Indeed, for a local inventory is possible to recorder the electrical energy consumption on the base of local energy production or considering all the electrical energy utilized from the mix in national network. The strictly geographical approach has made possible to attribute geothermal energy production to the correspondent Provinces, whereas this energy is put in the national electrical network and is not really used in loco.

The problem concerns the adoption of a territorial or responsibility approach in the allocation of the emissions [5] and this choice may become important especially at small scale, where the exchanges with the outside become bigger than the internal ones. 
The aim of this paper is to evaluate the importance of this emission saving, comparing to the other emission sources, considering both the approaches, the territorial and the responsibility one.

\section{Methods}

The IPCC methodology have been used to point out greenhouse gases emissions inventories, on the base of Revised Guideline 1996 [6] with the update "Good Practice Guidance and Uncertainty Management" [7] and the "Good Practice Guidance for Land Use, Land-Use Change and Forestry" [8].

The GWP value in $\mathrm{CO}_{2}$ eq for $\mathrm{CH}_{4}$ and $\mathrm{N}_{2} \mathrm{O}$ used is the established ones in the Third Assessment Report (TAR) of 2001, respectively 23 for $\mathrm{CH}_{4}$ and 296 for $\mathrm{N}_{2} \mathrm{O}$.

As a first result we show emission inventories developed considering the electrical consumption from national mix. In a second balance, geothermal energy production has been considered used in the two Provinces in accordance with a strictly geographical approach.

\subsection{Input data}

It has been possible to use, for the majority of the emissions sources, data at local scale, from the national data base and reports for year 2000.

In the energy sector we consider the emissions produced by direct combustion of fuels and electrical energy consumption. This is not a double counting case because in the two Provinces there are no power plants except for the geothermal ones. An average value of greenhouse gas production in $\mathrm{kg} \mathrm{CO}_{2} \mathrm{eq} / \mathrm{kWh}$ has been estimated starting from the national amount of fuels consumed for power production [9]. Data on fuels and energy consumption are on provincial scale [10]. Only for Siena Province, is considered in energy sector the combustion emissions from an incinerator plant with energy saving [11].

Siena and Grosseto Provinces have a prosperous agricultural activity, so this is an important sector. Data both for animal breeding and management as well as from fertilizers and manure use are from Agriculture Census 2000 [12] at provincial scale.

Waste and wastewater production and management data have been found in nation reports [11] with data at provincial scale for solid waste disposals, wastewater purification treatments. Up to now Grosseto has an incinerator plant without energy saving.

The industrial sector is not relevant for Grosseto Province greenhouse emissions and for Siena the only industry considered is the crystal production in Colle Val d'Elsa [13] that cover by itself the $15 \%$ the worldwide production and the $95 \%$ of the Italian.

For the $\mathrm{CO}_{2}$ absorption by forest annual growth Regional Forest Inventory 1998 [14] has been used for woodland in ha and we used also a local measured value for the woods growth rate (Table 1). 
South Tuscany forests are typically constituted by oak woods and Mediterranean shrublands. Provincial Section of State Forestry Department data have been used for forest exploitation in 2000 in $\mathrm{t} 10^{3}$ for wood type.

In the first balance we used the IPCC procedure and we obtained the net emissions subtracting forest absorption from total emissions and using the national emission for GWh for electrical energy consumption. In the second balance we adopt a strictly geographical approach for electrical energy consumption. We have considered electrical production from geothermal used in loco, so the electrical consumption of the Provinces covered from geothermal production is not considered in the inventory.

Table 1: $\quad$ Wood type and annual rate growth $\mathrm{m}^{3} \mathrm{dm} /$ year [14].

\begin{tabular}{|l|r|r|r|}
\hline & \multicolumn{2}{|c|}{ Forest surface \% } & \\
\hline Wood type & SI & GR & \multicolumn{2}{|c|}{$\begin{array}{c}\text { Rate growth } \mathbf{~ m}^{\mathbf{3}} \\
\text { dm/year }\end{array}$} \\
\hline Turkey oak & 36.32 & 30.03 & 6.4 \\
\hline Holm-oak & 12.18 & 8.07 & 5.8 \\
\hline Pubescent Oak & 19.07 & 7.57 & 4.7 \\
\hline Chestnut & 5.10 & 4.55 & 9.1 \\
\hline Beech & 0.65 & 1.17 & 9.9 \\
\hline Hornbeam & 0.73 & 1.72 & 4.6 \\
\hline Other woods & 8.56 & 8.26 & 2.6 \\
\hline Mediterranean scrubland & 17.39 & 38.63 & 2.6 \\
\hline
\end{tabular}

\section{Results and discussion}

The greenhouse gas emissions have been estimated on the base of IPCC methodology for the five sectors for year 2000. The first balance, with electrical energy emissions included, is presented in Tables 2; the indirect greenhouse gases are reported out of the balance calculation.

As it is shown in the tables, energy sector is largely the most important source of emissions in both Provinces, due also to the very low industries presence. We discuss energy sector in detail in the next section.

The second sector for importance is waste sector for $\mathrm{CH}_{4}$ emissions from solid waste disposal sites and wastewater treatments. Siena has a lower $\mathrm{CH}_{4}$ production despite the higher population due to a lower waste production and a higher urban waste differentiated collection.

Then in the agricultural sector both $\mathrm{N}_{2} \mathrm{O}$ emissions from fertilizers use and $\mathrm{CH}_{4}$ from breeding enteric fermentation are significant. In this case the higher emissions in Grosseto Province depend on the main weight of agriculture in the economy of this area.

The industry sector is not significant in both the Province, based principally on tertiary sector, tourism and in second play on agriculture. Only in Siena Province is relevant crystal production that has as process emissions NMVOC. 
The role of $\mathrm{CO}_{2}$ adsorption by forests is very important in the two Provinces, since both have $41 \%$ of the territory covered by forest lands, and this $\mathrm{CO}_{2}$ abatement arises to cover almost all the $\mathrm{CO}_{2}$ emissions from energy sector.

The index $\mathrm{t} \mathrm{CO}_{2}$ eq/inab resumes all this emissions in base to the Province population, and Grosseto has a lower index value, due mainly to minor energy consumption. The ratio between MWh of electrical energy consumption and population is 4.2 for Siena and 3.7 for Grosseto.

Table 2: $\quad$ Siena and Grosseto emission balances in $2000\left(\mathrm{Gg} \mathrm{CO}_{2} \mathrm{eq}\right)$.

\begin{tabular}{|c|c|c|c|c|c|c|c|c|}
\hline Siena & $\mathrm{CO}_{2}$ & $\mathrm{CH}_{4}$ & $\mathrm{~N}_{2} \mathrm{O}$ & $\mathrm{NO}_{2}$ & $\mathrm{NO}_{\mathrm{x}}$ & $\mathrm{CO}$ & NMVOC & Total \\
\hline & $\mathrm{Gg}$ & $\begin{array}{c}\mathrm{Gg} \\
\mathrm{CO}_{2} \text { eq }\end{array}$ & $\begin{array}{c}\mathrm{Gg} \\
\mathrm{CO}_{2} \text { eq }\end{array}$ & $\mathrm{Gg}$ & $\mathrm{Gg}$ & $\mathrm{Gg}$ & $\mathrm{Gg}$ & $\begin{array}{c}\mathrm{Gg} \\
\mathrm{CO}_{2} \text { eq. }\end{array}$ \\
\hline Energy & $1,574.7$ & 3.7 & 2.9 & 0.010 & 6.930 & 39.562 & 7.495 & $1,581.3$ \\
\hline Agriculture & 0.0 & 60.3 & 188.1 & 0.635 & 0.035 & 0.931 & & 248.4 \\
\hline Waste & 0.0 & 347.6 & 2.3 & 0.008 & & & & 349.9 \\
\hline Forest & $-1,135.4$ & & & & & & & \\
\hline Industry & 0.0 & 0.0 & 0.0 & & & & 0.077 & \\
\hline \multicolumn{8}{|c|}{ Total emissions $\mathrm{Gg} \mathrm{CO}_{2}$ eq } & $2,179.5$ \\
\hline \multicolumn{8}{|c|}{ Total net emissions $\mathrm{Gg} \mathrm{CO}_{2}$ eq } & $1,044.3$ \\
\hline \multicolumn{8}{|c|}{$\mathrm{t} \mathrm{CO}_{2}$ eq. /inhab. } & 4.11 \\
\hline
\end{tabular}

\begin{tabular}{|c|c|c|c|c|c|c|c|c|}
\hline Grosseto & $\mathrm{CO}_{2}$ & $\mathrm{CH}_{4}$ & $\mathrm{~N}_{2} \mathrm{O}$ & $\mathrm{NO}_{2}$ & $\mathrm{NO}_{\mathrm{x}}$ & $\mathrm{CO}$ & NMVOC & Total \\
\hline & Gg & $\begin{array}{c}\mathrm{Gg} \\
\mathrm{CO}_{2} \text { eq. }\end{array}$ & $\begin{array}{c}\mathrm{Gg} \\
\mathrm{CO}_{2} \text { eq. }\end{array}$ & $\mathrm{Gg}$ & $\mathrm{Gg}$ & Gg & Gg & $\begin{array}{c}\mathrm{Gg} \\
\mathrm{CO}_{2} \text { eq. }\end{array}$ \\
\hline Energy & $1,130.8$ & 2.8 & 2.2 & 0.007 & 5.148 & 32.280 & 6.095 & 1135.7 \\
\hline Agriculture & 0.0 & 124.7 & 195.9 & 0.662 & 0.034 & 0.922 & & 320.6 \\
\hline Waste & 2.5 & 378.6 & 2.0 & 0.007 & & & & 383.2 \\
\hline Forest & $-1,079.7$ & & & & & & & \\
\hline Industry & 0.0 & 0.0 & 0.0 & & & & & \\
\hline \multicolumn{8}{|c|}{ Total emissions $\mathrm{Gg} \mathrm{CO}_{2}$ eq } & 1839.5 \\
\hline \multicolumn{8}{|c|}{ Total net emissions $\mathrm{Gg} \mathrm{CO}_{2}$ eq } & 759.8 \\
\hline \multicolumn{8}{|c|}{$\mathrm{t} \mathrm{CO}_{2}$ eq. /inhab } & 3.5 \\
\hline
\end{tabular}

\subsection{Energy sector}

The energy sector emissions are constituted by fuel combustion and electrical energy consumption, plus incinerator emissions for Siena Province. The majority of all the emissions are from fuels combustion, with $63.8 \%$ for Siena and $63 \%$ for Grosseto of all the energy emissions. The fuel direct combustion includes commercial, industrial, domestic, agricultural and transport that is the main use, as we see for Siena in Figure 2. 
The lasting energy emissions (36\% and 37\%) are emitted by electrical production of energy consumed by the Provinces, calculated from average national emissions in $\mathrm{Gg} \mathrm{CO}_{2}$ eq for $\mathrm{GWh}$. In 2000 the national electrical production has been obtained $79.7 \%$ thermoelectrically, $18.8 \%$ hydroelectrically, $1.7 \%$ by geothermal energy and $0.2 \%$ by wind ad solar. The emission factor for electrical energy in 2000 is $0.528 \mathrm{Gg} / \mathrm{GWh} \mathrm{CO}_{2}$ eq, and it has then been multiplied for provincial electrical consumption. In Figure $3 \mathrm{Gg} \mathrm{CO}_{2} \mathrm{eq}$ emissions from electrical energy consumption by sector for Siena Province are shown.

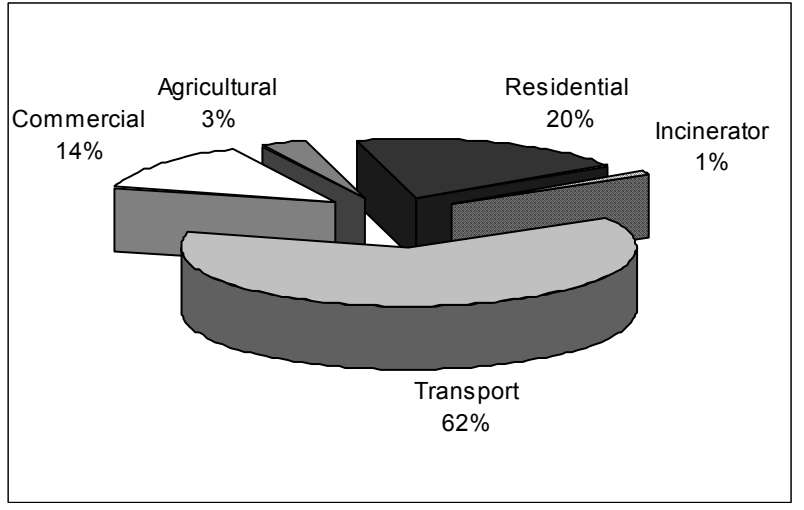

Figure 2: Total fuels emissions in Siena Province in 2000 by sector.

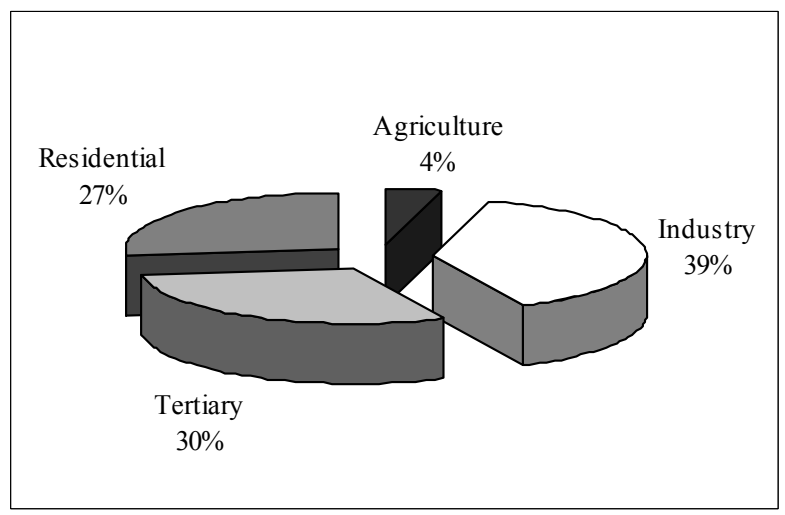

Figure 3: $\quad \mathrm{Gg} \mathrm{CO}_{2}$ eq emissions from electrical energy consumption by sector for Siena Province in 2000.

The total energy sector emissions are $73 \%$ for Siena and $62 \%$ for Grosseto on total emissions inventoried. The only electricity consumption emissions are equal respectively to $26 \%$ (SI) and $23 \%$ (GR) on the total emissions value (Table 3). 
If now a strictly geographical approach is used for electrical consumption in both Provinces and all the geothermal production is attributed to the area where the power plants are collocated, we can outline a new emissions balance.

Taking into consideration the geothermal power plants production and the electrical consumption trend from 1999 to 2004, shown in Figure 1, we see a complete coverage for provincial electricity consumption for year 2000 .

Table 3: $\quad$ Energy sector detail for Siena and Grosseto Provinces.

\begin{tabular}{|l|r|r|}
\hline $\begin{array}{c}\text { Energy sector emissions } \\
\left(\mathrm{Gg} \mathrm{CO}_{2} \mathrm{eq}\right)\end{array}$ & \multicolumn{1}{c|}{ SI } & \multicolumn{1}{c|}{ GR } \\
\hline Fuel combustion & 1016.4 & 719.5 \\
\hline Electricity & 564.8 & 416.3 \\
\hline Total Energy & 1581.2 & 1135.7 \\
\hline Total emissions & $\mathbf{2 , 1 7 9 . 5}$ & $\mathbf{1 8 3 9 . 5}$ \\
\hline Energy sector & $73 \%$ & $62 \%$ \\
\hline Electrical energy consumption & $26 \%$ & $23 \%$ \\
\hline
\end{tabular}

In this way, the emissions reduction is equal to the total emissions from electricity consumption.

The new net balance becomes $479.3 \mathrm{Gg} \mathrm{CO}_{2}$ eq with $1.89 \mathrm{t} \mathrm{CO}_{2} \mathrm{eq} /$ inhab for Siena and $343.5 \mathrm{Gg} \mathrm{CO}_{2}$ eq with $1.59 \mathrm{t} \mathrm{CO}_{2} \mathrm{eq} /$ inhab for Grosseto (Figure 4). The reduction in the second net balance is equal to $54 \%$ in both Provinces, and the new values for $\mathrm{t} \mathrm{CO}_{2} \mathrm{eq} /$ inhab are very low compared to other Italian Provinces.

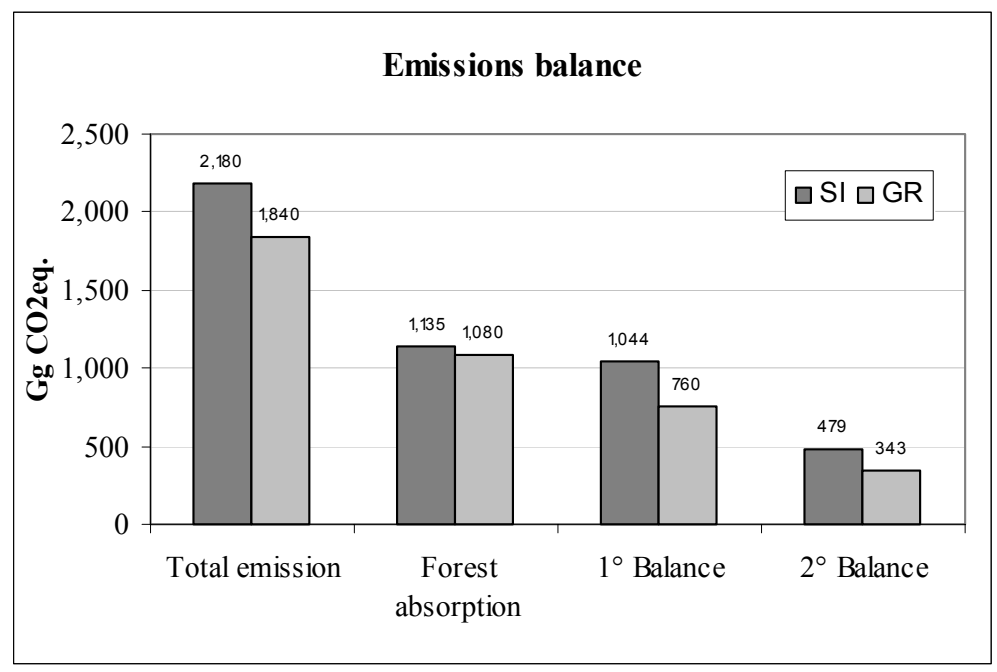

Figure 4: Greenhouse gas emissions inventories for Siena and Grosseto Provinces. 


\section{Conclusions}

We have demonstrated how the approach chosen in draw up electrical energy consumption in a greenhouse gas emissions inventory can change to a great degree the emissions balance. In our case, applying this assumption to electrical energy consumption to a country with a renewable energy source in its territory, we can see an important difference.

The variation in result in applying a responsibility approach and then a strictly geographical approach to electrical energy consumption is over the $54 \%$ of the net balance, indeed, the two Provinces became autonomous for electrical energy for year 2000 .

The comparison between the two approaches may be useful at local scale to comprise the real situation of greenhouse gas emissions. The results can help in identifying the sectors responsible of the real local emissions and consequently the sectors where further reductions are possible.

\section{References}

[1] Mirasgedis S., Sarafidis Y., Georgopoulou E., Lalas D.P., The role of renewable energy sources within the framework of the Kyoto Protocol: the case of Greece. Renewable and Sustainable Energy Reviews, 6, pp. 249-272, 2002.

[2] EurObserv'ER, Le baromètre géothermie, Système Solaires n 170, 2005.

[3] Romagnoli P., Personal communication, 5 September 2006, Enel.

[4] Ridolfi R., Kneller M., Donati A., Pulselli R.M, The greenhouse gas bilance of the Province of Siena. Journal of Environmental Management. Available on line 23 October 2006.

[5] Bastianoni S., Pulselli F.M., Tiezzi E., The problem of assigning responsibility for greenhouse gas emissions. Ecological Economics, 49, pp 253-257, 2004.

[6] Intergovernmental Panel on Climate Change (IPCC), Houghton J.T., Meira Filho L.G., Lim B., Tréanton K., Mamaty I., Bonduki Y., Griggs D.J. and Callander B.A. Revised 1996 IPCC Guidelines for National Greenhouse Inventories. IPCC/OECD/IEA, Paris, France, 1997.

[7] Intergovernmental Panel on Climate Change (IPCC), Penman J., Kruger D., Galbally I., Hiraishi T., Nyenzi B., Emmanuel S., Buendia L., Hoppaus R., Martinsen T., Meijer J., Miwa K., and Tanabe K. (Eds). Good Practice Guidance and Uncertainty Management in National Greenhouse Gas Inventories. IPCC/OECD/IEA/IGES, Hayama, Japan, 2000 .

[8] Intergovernmental Panel on Climate Change (IPCC), Penman J., Gytarsky M., Hiraishi T., Krug, T., Kruger D., Pipatti R., Buendia L., Miwa K., Ngara T., Tanabe K., Wagner F., Good Practice Guidance for Land Use, land-Use Change and Forestry IPCC/IGES, Hayama, Japan, 2003.

[9] Terna, 2000. www.terna.it/ita/statistiche/ 
[10] DGRM, 2000. www.dgerm.attivitaproduttive.gov.it

[11] ANPA, ONR, 2001. Rapporto Rifiuti 2001. Roma.

[12] ISTAT, Quinto Censimento dell'Agricoltura. Istat, Roma, 2000. www.istat.it

[13] Bortot R., Analisi exergetica applicata a sistemi territoriali e produttivi. Degree Thesis. Academic year 2001-2002.

[14] Regione Toscana, Dipartimento dello sviluppo economico, Boschi e Macchie di Toscana, Regione Toscana, 1998. 